\title{
PRODUÇÃO CIENTÍFICA SOBRE INOVAÇÃO: O QUE TEM SIDO ABORDADO NOS CURSOS STRICTO SENSU DA ÁREA DE CIÊNCIAS CONTÁBEIS DO BRASIL?
}

\section{SCIENTIFIC PRODUCTION ABOUT INNOVATION: WHAT HAS BEEN APPROACHED IN THE STRICTO SENSU COURSES OF BRAZIL ACCOUNTING SCIENCE AREA?}

\author{
ALEXANDRE CORADINI RIBEIRO \\ Universidade Federal de Mato Grosso do Sul - UFMS \\ Mestrando em Ciências Contábeis pela Universidade Federal de Mato Grosso do Sul - UFMS \\ Orcid: http://orcid.org/0000-0002-3647-5521 \\ E-mail: alexandrecoradinir@gmail.com \\ EDICREIA ANDRADE DOS SANTOS \\ Universidade Federal do Paraná - UFPR \\ Doutora em Contabilidade - UFSC \\ Orcid: http://orcid.org/0000-0001-8745-3579 \\ E-mail: edicreiaandrade@yahoo.com.br \\ Endereço: Av. Prefeito Lothário Meissner, 632 - Campus III \\ Jardim Botânico, CEP. 80.210-170 - Curitiba, PR - Brasil
}

\section{RESUMO}

O objetivo deste estudo é analisar como estão as discussões sobre inovação evidenciadas nos trabalhos de conclusão dos cursos stricto sensu (mestrado e doutorado) em contabilidade no Brasil por meio de uma revisão sistemática baseada na metodologia Preferred Reporting Items for Systematic Reviewsand Meta-Analyses (PRISMA) (Moher et al., 2009). Após a consulta no Banco de Teses e Dissertações da CAPES a respeito da temática inovação, identificou-se 68 estudos, dentre os quais foram realizadas as devidas exclusões, finalizando em um total de 27 pesquisas examinadas. A análise procedeu-se por meio da análise de conteúdo, dividida em duas etapas, sendo a primeira de levantamento quantitativo e a segunda de levantamento qualitativo. Os achados apontaram que o período de maior número de publicações foi o ano de 2018, com 11 trabalhos. Ressalta-se, também, a Universidade Regional de Blumenau (FURB) com 8 trabalhos, sendo que 6 são teses, além de possuir ao menos uma pesquisa desde o ano de 2012 até o ano de 2018, com exceção do ano de 2014. Apesar da escassez de estudos na área de inovação, identificaram-se diversas lacunas para pesquisas futuras relacionadas à temática. Destarte, como a presente pesquisa abrangeu apenas a área de Ciências Contábeis, sugere-se que estudos futuros possam analisar trabalhos de outras áreas, por exemplo, Administração.

Palavras-chave: Produção científica. Inovação. Ciências Sociais Aplicadas. Ciências Contábeis.

Data de submissão: 27/10/2019. Data de aceite: 08/12/2019. Data de publicação:17/12/2019. 


\begin{abstract}
The objective of this study is to analyze how are the discussions about innovation evidenced in the works of conclusion of the stricto sensu courses (masters and doctorate) in accounting in Brazil through a systematic review based on the methodology Preferred Reporting Items for Systematic Reviewsand Meta-Analyzes (PRISMA) ) (Moher et al., 2009). After consulting the CAPES Thesis and Dissertation Bank on thematic innovation, 68 studies were identified, including the appropriate exclusions, resulting in a total of 27 studies examined. The analysis was performed through content analysis, divided into two stages, the first of quantitative survey and the second of qualitative survey. The findings indicated that the period with the highest number of publications was 2018, with 11 papers. Also noteworthy is the Regional University of Blumenau (FURB) with 8 papers, 6 of which are theses, besides having at least one research from 2012 to 2018, except 2014. From the scarcity of studies in the area of innovation, several gaps were identified for future research related to the theme. Thus, as this research covered only the area of Accounting Sciences, it is suggested that future studies may analyze works from other areas, for example, Administration.
\end{abstract}

Keywords: Scientific production. Innovation. Applied Social Sciences. Accounting Sciences.

\title{
1 INTRODUÇÃO
}

A manutenção de vantagens competitivas no mercado, hodiernamente, exige das organizações constantes alterações em seus modelos de gestão, adaptando-se dessa forma, às novas exigências requeridas (PRADO, 2008). Organizações, de uma forma geral, buscam inovar seguidamente para a obtenção da diferenciação e vantagens competitivas, tanto pela melhoria nos serviços/produtos ofertados, quanto pela eficácia operativa (MACHADO, 2015).

Com relação aos estudos anteriores que abordam a temática inovação, pode-se destacar alguns como Zorzo (2015), Wojahn (2015) e Condeixa (2016). O primeiro autor buscou verificar se existe correlação entre o foco em inovação e os escores de eficiência econômica relativa. Com relação aos achados, destaca-se que há baixo nível de foco em inovação por parte das empresas estudadas. Além disso, não foi encontrado correlação significativa entre o nível de foco despendido em inovação e os escores de eficiência econômica relativa.

Por sua vez, Wojahn (2015) teve como objetivo, em sua pesquisa, realizar uma análise da influência da orientação empreendedora e da capacidade de aprendizagem organizacional no desempenho em inovação de produtos em empresas da indústria moveleira localizadas no Sul do Brasil. Os resultados obtidos evidenciam que tanto a orientação empreendedora quanto a aprendizagem organizacional foram confirmadas como determinantes da inovação em empresas da indústria moveleira, apresentando também resultados positivos quanto ao desempenho inovador e, consequentemente, no desempenho organizacional.

Frente a relevância das empresas de alto crescimento e a força da Ciência, Tecnologia e Inovação (CT\&I) sobre o crescimento econômico, Condeixa (2016) buscou esclarecer a relação entre os indicadores regionais de CT\&l e o empreendedorismo de alto crescimento. Dentre os achados de sua pesquisa, o autor verificou uma baixa correlação entre os indicadores estaduais de CT\&l e o empreendedorismo de alto crescimento regional.

Prado (2018) reforça que o processo de inovação pode ser composto por três partes distintas que andam em paralelo: desenvolvimento de tecnologia, desenvolvimento de produto e produção como um todo. Desse modo, estes processos são de grande importância 
para a evolução econômica e social de determinada região, envolvendo diversos setores como o financeiro, público e instituições de ensino, melhorando o desempenho econômico como um todo (PRADO, 2018). Sob esse viés, frente a relevância da inovação para economia e para sociedade em geral, o autor chama a atenção para a multiplicação de estudos que abordam o tema, em especial, com ênfase na área de Ciências Contábeis.

Assim, na busca de aprofundar o conhecimento científico referente a inovação e conhecer a evolução das pesquisas que abordam a temática, o presente estudo é pautado no seguinte questionamento: Qual é o cenário das discussões sobre inovação evidenciadas nos trabalhos de conclusão dos cursos stricto sensu (mestrado e doutorado) em contabilidade do Brasil? Para responder a essa pergunta, o objetivo geral deste estudo é analisar o cenário das discussões sobre inovação evidenciadas nos trabalhos de conclusão dos cursos stricto sensu (mestrado e doutorado) em contabilidade no âmbito nacional.

A justificativa teórica desta pesquisa centra-se na possibilidade de contribuir para o entendimento da inovação, a qual é abordada sob a ótica de diferentes áreas. Entretanto, é comum encontrar abordagens sobre inovação retratando-a como fator preponderante no intuito de promover vantagens competitivas para as organizações, como um determinante do sucesso organizacional, impactando no desempenho, podendo ser inovador e/ou financeiro.

Com relação a justificativa prática, esta pesquisa apoia-se no fato que a inovação é também um componente importante na produtividade de uma economia. Além disso, em grandes corporações e empreendimentos, a inovação é a base sobre a qual a riqueza pode ser criada e as estratégias devem ser construídas. Nesta direção, a contribuição se dá ao agregar novas perspectivas para que gestores e empresas possam avaliar a efetividade de suas decisões de investimentos em esforços para inovação.

\section{REVISÃO DA LITERATURA}

Na seção de revisão de literatura são efetuadas as considerações literárias e as posições de diversos autores, elaborada em uma única parte, na qual buscou-se evidenciar os conceitos e dimensões da inovação em conformidade com pesquisas desenvolvidas em âmbito nacional e internacional.

\subsection{INOVAÇÃO: CONCEITOS E DIMENSÕES}

Joseph Schumpeter foi um dos primeiros autores a abordar a temática inovação, partindo da diferenciação entre inovação e invenção. Uma invenção é entendida como algo novo, que pode ser uma ideia, um projeto novo de um produto (ou melhoramento), que se transforma em inovação a partir do momento em que essa novidade retorna por meio de benefícios econômicos para quem a introduziu (SCHUMPETER, 1988).

Outros pesquisadores seguem este entendimento. Betz (1998), por exemplo, aponta que os benefícios econômicos da invenção ocorrem a partir da inovação, por meio da inserção de novos produtos, processos ou serviços, viabilizando a exploração comercial do conhecimento. Além disso, o autor enfatiza que a capacidade de inovar das organizações classifica-se como um diferencial para o êxito econômico numa economia globalizada. Esse diferencial é um dos indicadores mais utilizados para avaliação da competitividade, pelo fato de que seus resultados se encontram relacionados à capacidade de conduzir as mudanças exigidas pelo mercado.

Por outro lado, é possível encontrar na literatura autores que não abordam a exploração comercial, como Rogers (1995) e Afuah (2003). Rogers (1995, p. 11) sugere que a 
inovação "[...] é uma ideia, prática ou objeto que é percebida como nova por um indivíduo ou por outra unidade de adotantes". Nesta direção, Afuah (2003) também não situa a relação econômica no âmbito da inovação e elucida a inovação como o uso ou a adoção de algo novo para a organização ou em âmbito global, para ofertar novos produtos ou serviços que os clientes irão precisar.

Sob essa perspectiva, Van de Ven (1986) argumenta que a inovação é entendida como a implementação e o desenvolvimento de novas ideias por pessoas ao longo do tempo e é voltado para quatro fatores básicos que incluem novas ideias, pessoas, transações e contexto institucional. Conforme Bessant e Tidd (2009), a inovação é o processo de tradução de ideias em produtos, processos ou serviços úteis e utilizáveis. Por sua vez, os autores evidenciam que a inovação pode assumir formas variadas, como a inovação no produto, nos processos, na posição e no paradigma. Essas dimensões são apresentadas como os 4Ps da inovação de acordo com o Quadro 1.

Quadro 1. Dimensões de mudança - os 4Ps da inovação.

\begin{tabular}{|c|l|}
\hline Inovação & \multicolumn{1}{|c|}{ Definição } \\
\hline Produto & Mudanças nas coisas (produtos/serviços) que uma empresa oferece. \\
\hline Processo & $\begin{array}{l}\text { Mudanças nas formas em que as coisas (produtos/serviços) são criadas e ofertadas ou } \\
\text { apresentadas ao consumidor. }\end{array}$ \\
\hline Posição & Mudanças no contexto em que produtos/serviços são introduzidos. \\
\hline Paradigma & Mudança nos modelos mentais básicos que norteiam o que a empresa faz. \\
\hline
\end{tabular}

Fonte: Adaptado de Pavão (2016).

O processo de inovação se baseia nos fatores de (i) geração de ideias, (ii) seleção das melhores e (iii) sua implementação (PAVÃO, 2016). Ele se inicia a partir da investigação no ambiente externo e interno da organização objetivando detectar e processar sinais de inovação. Desse modo, diferentes fontes de informação, tecnologia, e conhecimento são indispensáveis para a inovação (BECK, 2013). Com relação as fontes internas, elas abrangem as atividades direcionadas para o desenvolvimento de produtos e processos, enquanto fontes externas envolvem a aquisição de informações codificadas; consultorias especializadas; aquisição de licenças de fabricação de produtos; tecnologias embutidas em máquinas e equipamentos; além dos próprios fornecedores e clientes (TIGRE, 2006; COSTA; ROCHA, 2009).

Infere-se, portanto, que o termo inovação pode ser compreendido como um "processo de transformar ideias em realidade e lhes capturar o valor" (TIDD; BESSANT, 2015, p. 21). Tidd e Bessant (2015) enfatizam ainda, que as organizações necessitam da adoção de uma postura sábia para a gestão da inovação, estabelecendo várias estratégias capazes de unir o referido processo como um todo. Nesta perspectiva, a inovação é a habilidade da transformação das oportunidades em novas ideias e colocá-las em prática, ou seja, trata-se de tornar algo novo, renovar definições, ou introduzir uma novidade no mercado.

Com relação a gestão de empresas inovadoras, Dockhorn (2016) evidencia que elas buscam, em seu controle gerencial, atividades e informações para a gestão das organizações. Ainda segundo o autor, a inovação é a mudança que gera um novo padrão de desempenho para a empresa. Assim, a gestão é a capacidade de alinhar esforços com vistas a implementar uma iniciativa que orienta investimentos, define o foco de pesquisas e novos desenvolvimentos, gera valor e riqueza que transcendem ao negócio.

Sob esta perspectiva, para a eficácia de gestão de uma empresa inovadora são necessários alguns direcionamentos. Dentre eles pode-se mencionar a visão compartilhada e liderança; comunicação extensiva; indivíduos-chave; grupos de trabalho efetivo; 
desenvolvimento individual contínuo; estrutura apropriada; alto envolvimento em inovação; ambiente criativo; aprendizagem organizacional e foco no cliente (CORREIA, 2018).

\section{PROCEDIMENTOS METOdOLÓGICOS}

Esta pesquisa apresenta-se como uma revisão sistemática, planejada para responder uma pergunta específica e utiliza métodos explícitos para identificar e avaliar criticamente os estudos (CASTRO, 2001). Consoante Kitchenham (2004) a revisão sistemática da literatura consiste em uma maneira de identificar, avaliar, interpretar e sintetizar as pesquisas relevantes sobre determinada temática, além de evidenciar as lacunas na literatura e fornecer uma base para novas investigações.

Esta revisão foi conduzida conforme a metodologia Preferred Reporting Items for Systematic Reviewsand Meta-Analyses (PRISMA), a qual consiste em uma lista de itens a serem seguidos como protocolo (MOHER et al., 2009). A partir desta metodologia, para identificar os estudos acerca do assunto, realizou-se a busca com a palavra-chave "inovação" no banco de teses e dissertações da Coordenação de Aperfeiçoamento de Pessoal de Nível Superior (CAPES), o que resultou em 18.399 trabalhos. Vale ressaltar que a busca foi sem recorte temporal e realizada entre os meses de maio e junho de 2019.

Diante do alto número de pesquisas, procedeu-se com a limitação na área de conhecimento como "Ciências Sociais Aplicadas", e "Ciências Contábeis". Após a aplicação destes filtros foram identificados 68 estudos, sob os quais foram aplicados os critérios de exclusão (estudos que não abordaram explicitamente a temática, artigo em duplicidade e/ou anterior à Plataforma Sucupira e não encontrado em outros sites de busca), sendo que 41 trabalhos foram excluídos, resultando em 27 estudos a serem investigados conforme observase em Figura 1.

Figura 1 - Fluxograma das etapas para revisão sistemática.

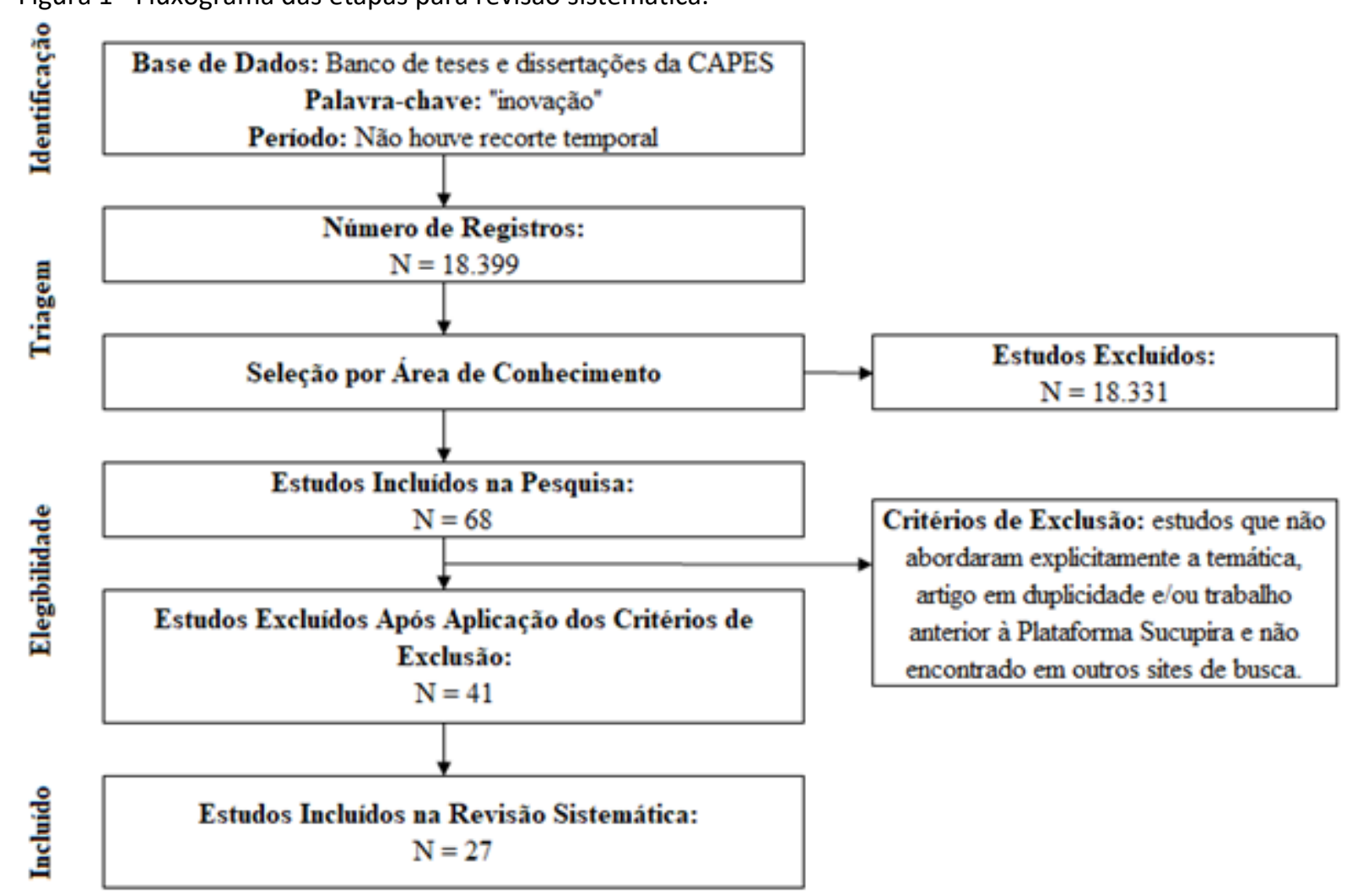

Fonte: Elaborado pelos autores com base no método Prisma (MOHER et al., 2009). 
Posteriormente, foram elencadas as características das pesquisas, de maneira quantitativa, por meio de estatística descritiva, com relação à quantidade de pesquisas por ano de publicação, por programa de pós-graduação e por instituição. Além disso, foram avaliados os principais resultados da produção científica, de forma qualitativa, quanto aos objetivos e os resultados do estudo. Por fim, com o intuito de explorar áreas inovadoras ainda carentes de estudo, foram evidenciadas lacunas para pesquisas futuras.

\section{ANÁLISE DOS RESULTADOS}

Nesta seção são descritos os achados, tendo em vista as características das teses e dissertações, da quantidade de publicação por ano, por programa de pós-graduação e por instituição. Além disso, foram apontados os principais achados e evidenciaram-se as contribuições e lacunas para futuras pesquisas.

\subsection{ANÁLISE QUANTITATIVA}

Faz-se mister, em um primeiro momento, salientar o número de Programas de PósGraduação relacionados a área de Ciências Contábeis. De acordo com o Relatório da Avaliação Quadrienal da CAPES divulgado no ano de 2017, são 28 programas espalhados pelo Brasil que são divididos em Programa de Pós-Graduação em Ciências Contábeis, Programa de PósGraduação em Administração e Ciências Contábeis, Programa de Pós-Graduação em Contabilidade, Programa de Pós-Graduação em Controladoria, Programa de Pós-Graduação em Controladoria e Contabilidade, Programa de Pós-Graduação em Ciências Contábeis e Administração e, Programa de Pós-Graduação em Ciências Contábeis e Atuariais.

Nesta direção, foram identificados os programas de pós-graduação de origem das teses e dissertações, sendo que a busca foi realizada com ênfase na área citada anteriormente. Assim, a maioria das dissertações é do Programa de Mestrado em Ciências Contábeis com 7 trabalhos, seguido por Mestrado em Ciências Contábeis e Administração com 6, Mestrado em Contabilidade com 3, Mestrado em Controladoria com 2 e por fim, Mestrado em Controladoria e Contabilidade 1 trabalho. Entre as teses, destacaram-se os Programas de Doutorado em Ciências Contábeis com 6 trabalhos e Doutorado em Controladoria e Contabilidade, com 2 trabalhos.

Como evidenciado anteriormente, foram selecionados 27 estudos que abordam a temática inovação. O Gráfico 1 evidencia a quantidade de trabalhos por ano e evidencia que 19 estudos (70,37\%) são em nível de mestrado (dissertações) enquanto 29,63\% em nível de doutorado, ou seja, 8 teses.

Gráfico 1 - Quantidade de trabalhos no período entre 2012 e 2018.

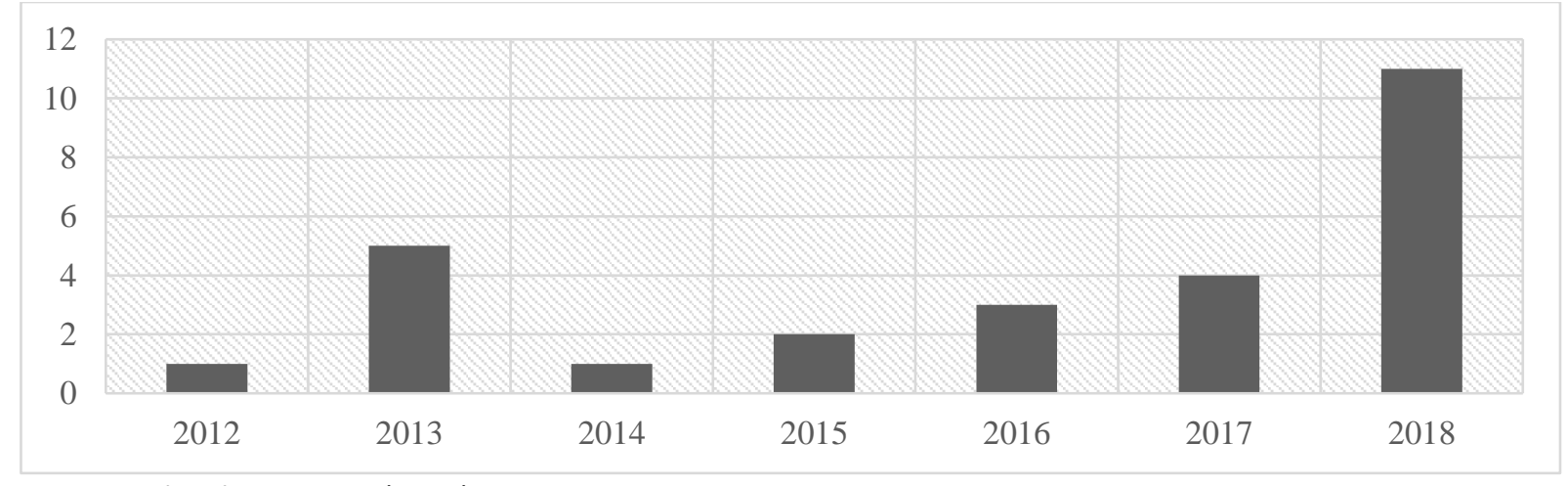

Fonte: Dados da pesquisa (2019). 
Com relação as instituições que ofertam estes programas de pós-graduação, destacase a Universidade Regional de Blumenau (FURB) com 8 trabalhos, seguida pela Universidade Comunitária da Região de Chapecó (UNOCHAPECÓ) com 6, Universidade Federal de Santa Catarina (UFSC) com 3, Universidade de São Paulo (USP), Pontifícia Universidade Católica de São Paulo (PUC-SP) e Universidade Federal Rural de Pernambuco (UFRPE) com 2 cada e, Universidade Federal da Bahia (UFBA), Universidade Federal do Rio Grande do Sul (UFRGS), Universidade Estadual de Maringá (UEM) e Fundação Escola de Comércio Álvares Penteado (FECAP) com 1 trabalho cada.

\subsection{ANÁLISE QUALITATIVA}

Na presente seção buscou-se relacionar as teses e dissertações, visando identificar prováveis contribuições e lacunas de pesquisa, para estimular novos pesquisadores a adotarem o tema inovação em estudos futuros e, consequentemente, contribuir para a construção do conhecimento científico acerca da temática. A Tabela 1 apresenta as dissertações e as teses que foram objeto deste estudo.

Tabela 1 - Teses e Dissertações sobre Inovação.

\begin{tabular}{|c|c|c|c|c|}
\hline $\mathbf{N}^{\circ}$ & Natureza & Título & Autor/Ano & Instituição \\
\hline 1 & Dissertação & $\begin{array}{l}\text { Relação do uso interativo de instrumentos do sistema } \\
\text { de controle gerencial com diferentes modelos de } \\
\text { gestão de inovação de empresas. }\end{array}$ & Utzig (2012) & FURB \\
\hline 2 & Dissertação & $\begin{array}{l}\text { Inovação tecnológica e estrutura de capital: um estudo } \\
\text { em empresas brasileiras de capital aberto. }\end{array}$ & Abreu (2013) & UFBA \\
\hline 3 & Dissertação & $\begin{array}{l}\text { Interfaces da folga organizacional com inovação: um } \\
\text { estudo em empresa têxtil. }\end{array}$ & Beck (2013) & FURB \\
\hline 4 & Tese & $\begin{array}{l}\text { Cultura de inovação e sua influência no desempenho } \\
\text { em inovação de produtos na indústria têxtil de Santa } \\
\text { Catarina. }\end{array}$ & Gomes (2013) & FURB \\
\hline 5 & Dissertação & $\begin{array}{l}\text { Estudo das fontes de financiamentos públicas dos } \\
\text { processos ou projetos de inovação. }\end{array}$ & Scholz (2013) & PUC-SP \\
\hline 6 & Tese & $\begin{array}{l}\text { Utilização da informação contábil na adesão aos } \\
\text { incentivos fiscais de inovação tecnológica } \\
\text { estabelecidos pela Lei } N^{\circ} 11.196 / 2005 \text {. }\end{array}$ & Zucchi (2013) & USP \\
\hline 7 & Tese & $\begin{array}{l}\text { Estilo de liderança, sistema de controle gerencial e } \\
\text { inovação tecnológica: papel dos sistemas de crenças, } \\
\text { interativo, diagnóstico e de restrições. }\end{array}$ & Cruz (2014) & USP \\
\hline 8 & Dissertação & $\begin{array}{l}\text { Incentivos fiscais à pesquisa, desenvolvimento e } \\
\text { inovação tecnológica no Brasil: uma análise da Lei Do } \\
\text { Bem. }\end{array}$ & Faccini (2015) & PUC-SP \\
\hline 9 & Tese & $\begin{array}{l}\text { Aprendizagem organizacional e sua relação com o } \\
\text { desempenho em inovação de produtos moderada } \\
\text { pelas capacidades dinâmicas. }\end{array}$ & Machado (2015) & FURB \\
\hline 10 & Tese & $\begin{array}{l}\text { Influência da cultura organizacional na relação entre } \\
\text { estrutura formal para inovação e processo criativo: } \\
\text { estudo em ambientes organizacionais. }\end{array}$ & Dockhorn (2016) & FURB \\
\hline 11 & Dissertação & $\begin{array}{l}\text { A influência da estratégia, tecnologia e inovação na } \\
\text { gestão dos custos da qualidade e no desempenho: um } \\
\text { levantamento em empresas do APL de confecções. }\end{array}$ & Pavão (2016) & UEM \\
\hline 12 & Tese & $\begin{array}{l}\text { Relação entre capacidade de absorção, inovação e } \\
\text { desempenho competitivo, moderada pela aliança } \\
\text { estratégica. }\end{array}$ & Silva (2016) & FURB \\
\hline 13 & Dissertação & $\begin{array}{l}\text { Atuação prática em inovação: um estudo em uma } \\
\text { indústria agroalimentar do Oeste Catarinense. }\end{array}$ & Lappe (2017) & UNOCHAPECÓ \\
\hline
\end{tabular}




\begin{tabular}{|c|c|c|c|c|}
\hline 14 & Dissertação & $\begin{array}{l}\text { Influência de pressões ambientais na formação de } \\
\text { redes mediada pelo sistema de controle gerencial em } \\
\text { incubadoras de empresas. }\end{array}$ & Lopes (2017) & UFSC \\
\hline 15 & Tese & $\begin{array}{l}\text { Relação das ações estruturantes com o desempenho } \\
\text { em inovação mediadas pela dinâmica da maturidade } \\
\text { das capacidades em inovação. }\end{array}$ & Picolo (2017) & FURB \\
\hline 16 & Dissertação & $\begin{array}{l}\text { Relação entre inovação e adoção de práticas } \\
\text { modernas de Contabilidade Gerencial. }\end{array}$ & Souza (2017) & UFSC \\
\hline 17 & Dissertação & $\begin{array}{l}\text { Inovação e mudança na auditoria interna do Instituto } \\
\text { Federal de Educação, Ciência e Tecnologia De } \\
\text { Pernambuco: a contribuição da investigação } \\
\text { apreciativa. }\end{array}$ & Aquino (2018) & UFRPE \\
\hline 18 & Tese & $\begin{array}{l}\text { Influência da maturidade em responsabilidade social } \\
\text { corporativa e inovação sustentável no desempenho de } \\
\text { empresas brasileiras. }\end{array}$ & Bacinello (2018) & FURB \\
\hline 19 & Dissertação & \begin{tabular}{|l} 
Estudo das contribuições das ações de \\
desenvolvimento e fortalecimento de startups do \\
Projeto StartupSC.
\end{tabular} & Bernardi (2018) & UNOCHAPECÓ \\
\hline 20 & Dissertação & $\begin{array}{l}\text { Estudo de caso: papel da controladoria na gestão de } \\
\text { empresas inovadoras. }\end{array}$ & Correia (2018) & FECAP \\
\hline 21 & Dissertação & $\begin{array}{l}\text { Do artesanal ao profissional: tipologia e capacidades } \\
\text { estratégicas das microcervejarias da mesorregião do } \\
\text { Oeste Catarinense. }\end{array}$ & Cunico (2018) & UNOCHAPECÓ \\
\hline 22 & Dissertação & $\begin{array}{l}\text { Influência da resiliência do gestor na formação de } \\
\text { redes moderada pela prioridade estratégica de } \\
\text { inovação em empresas incubadas. }\end{array}$ & Gomes (2018) & UFSC \\
\hline 23 & Dissertação & $\begin{array}{l}\text { Ecossistemas de inovação: estudo da região de } \\
\text { Chapecó. }\end{array}$ & Koch (2018) & UNOCHAPECÓ \\
\hline 24 & Dissertação & $\begin{array}{l}\text { Inovação nas indústrias de confecções da região Oeste } \\
\text { De Santa Catarina. }\end{array}$ & Menegon (2018) & UNOCHAPECÓ \\
\hline 25 & Dissertação & $\begin{array}{l}\text { Inovação nas indústrias vitivinícolas do Alto Vale Do } \\
\text { Rio Do Peixe/Sc. }\end{array}$ & Prado (2018) & UNOCHAPECÓ \\
\hline 26 & Dissertação & $\begin{array}{l}\text { Potenciais modelos de negócios disruptivos para a } \\
\text { área contábil. }\end{array}$ & Schiavi (2018) & UFRGS \\
\hline 27 & Dissertação & $\begin{array}{l}\text { Delineamento da controladoria segundo a perspectiva } \\
\text { da abordagem apreciativa: a experiência em uma } \\
\text { instituição de ensino superior. }\end{array}$ & Souza (2018) & UFRPE \\
\hline
\end{tabular}

Fonte: Dados da Pesquisa (2019).

Observa-se que a Universidade Regional de Blumenau (FURB) teve ao menos uma pesquisa desde o ano de 2012 até o ano de 2018, com exceção do ano de 2014. Estes achados chamam a atenção pelo fato de a instituição promover, cada vez mais, estudos que abordam a temática inovação nos cursos stricto sensu da área de Ciências Contábeis. Nesta direção, na próxima seção apresenta-se as contribuições e lacunas de cada pesquisa, inclusive, da instituição acima citada.

\subsection{CONTRIBUIÇÕES E LACUNAS DE PESQUISA}

A seguir apresentam-se as contribuições e alguns direcionamentos de pesquisas futuras suportadas pelos estudos analisados.

A pesquisa de Souza (2017) teve por objetivo verificar a relação entre inovação e adoção de práticas modernas de contabilidade gerencial em empresas beneficiadas por auxílio financeiro de órgãos de apoio ao desenvolvimento de inovações. Os achados indicam, em relação à inovação, que as organizações estão mais envolvidas com as dimensões 
compromisso com a inovação, ambiente físico e atuação em equipe e, adicionalmente, que a maioria das organizações pesquisadas possui característica inovadora moderada. Nesta direção, a autora recomenda que futuras pesquisas utilizem amostra diferente da estudada, como empresas que tenham recebido prêmios de inovação ou que sejam consideradas como empresas inovadoras pelo mercado.

Gomes (2018) analisou a influência da resiliência do gestor na formação de redes moderada pela prioridade estratégica de inovação de empresas incubadas. Dentre os resultados da pesquisa, elucidou-se que a confiança nas decisões da equipe influencia positivamente o perfil defensor do gestor, ou seja, quanto maior a confiança do gestor da incubada nas decisões de sua equipe, mais o gestor é caracterizado pela tipologia estratégica defensora. Além disso, a autora constatou que após a inserção da variável moderadora prioridade estratégica de inovação, as relações entre a resiliência do gestor e a formação de redes são alteradas. Para futuras pesquisas, sugere-se a análise da relação entre as características resilientes dos gestores no momento de mudança estratégica, de defensor para prospector, e seu reflexo na formação de redes, desempenho ou outras variáveis.

Correia (2018), teve por objetivo identificar o papel da Controladoria na gestão de empresas inovadoras. A principal contribuição deste trabalho foi a ampliação do entendimento sobre a atuação da controladoria na gestão de organizações inovadoras, o alto grau de complexidade das interações e a velocidade com que as oportunidades surgem; isso transforma o ambiente organizacional em altamente desafiador e requer dos profissionais que trabalham na controladoria, além de versatilidade, conhecimento amplo, tanto de controladoria quanto de outras áreas, e agilidade no atendimento.

Em sua pesquisa, Prado (2018) buscou analisar o desenvolvimento da inovação nas indústrias vitivinícolas do Alto Vale do Rio do Peixe, na perspectiva de proporcionar subsídios para a proposição de políticas públicas e outras iniciativas que possam auxiliar e incentivar o desenvolvimento desse setor. Os achados indicam que o percentual de empresas inovadoras é reduzido, limitando-se apenas a aquelas que possuem melhor estrutura e maior abrangência de mercado, representando $30 \%$ do total de vinícolas participantes. Mesmo entre as empresas que mantém atividades de inovação, observou-se a ausência de controles sobre os investimentos e os resultados das suas inovações. Para estudos futuros, a autora sugere a aplicação da pesquisa a todas as vinícolas de todos os municípios da região estudada, e posterior verificação de semelhanças e diferenças entre elas.

A pesquisa de Schiavi (2018) evidencia as características dos potenciais modelos de negócios disruptivos atualmente existentes no mercado contábil nacional. Por meio dos resultados obtidos, percebe-se que algumas empresas contábeis estão surgindo com características de disrupção nos negócios, entretanto, os tradicionais modelos de negócios contábeis ainda estão sendo pouco perturbados por esses novos negócios. Nota-se, também, o uso intensivo de diferentes recursos tecnológicos nas atividades contábeis desses novos negócios. Por fim, a autora recomenda para estudos futuros, a ampliação na quantidade de empresas analisadas, bem como a replicação deste estudo em outras áreas.

Cunico (2018) analisou a relação percebida entre a tipologia estratégica e as capacidades estratégicas em microempresas do ramo cervejeiro da mesorregião do oeste catarinense. Os resultados obtidos pela autora indicam a presença de todos os tipos estratégicos nas respostas angariadas, em que o comportamento prospector apresenta-se como predominante seguido do tipo analítico e defensivo. Quanto às capacidades estratégicas, as que mais obtiveram destaque foram a capacidade de orientação ao mercado, a gerencial e a tecnológica. Como recomendações para pesquisas futuras, foi sugerido a 
realização de um estudo longitudinal para verificar se as empresas classificadas nesta pesquisa permaneceram nos comportamentos estratégicos identificados ou se houve alterações.

Em sua tese, Bacinello (2018) avaliou a influência da Maturidade em Responsabilidade Social Corporativa (MRSC), em conjunto com a maturidade em inovação sustentável, no desempenho empresarial. Por meio dos achados pode-se verificar a existência de uma forte relação positiva e direta entre essas duas perspectivas. Como recomendações para estudos futuros, uma possível abordagem seria a replicação dos modelos desenvolvidos neste estudo, em sua íntegra ou de forma individualizada, a setores empresariais específicos ou empresas de médio porte para constatação dos resultados aqui obtidos.

Utzig (2012) objetivou identificar a relação entre o nível do uso interativo de instrumentos do Sistema de Controle Gerencial (SCG) com os modelos de gestão da inovação propostos por Roussel, Saad e Erickson (1991) em empresas industriais brasileiras. Dentre os achados, evidenciou-se que as variáveis analisadas apresentam relação positiva, sugerindo que o uso interativo de instrumentos do sistema de controle gerencial adequados aos modelos de gestão de inovação explica o nível de inovação no lançamento e desenvolvimento de produtos das empresas pesquisadas. Nesta direção, recomenda-se para futuros estudos reaplicar o estudo em outras empresas do país, a fim de constatar similitudes e dissimilitudes.

Por sua vez, Souza (2018) em sua dissertação analisou como a investigação apreciativa pode contribuir para o processo de inovação e mudança em decorrência da implantação de uma controladoria na Faculdade de Ciências Humanas e Sociais de Igarassu (FACIG). Sob este direcionamento, chegou-se à construção da visão de futuro que resultará na implantação de uma controladoria na FACIG, como símbolo da inovação e mudança em seu contexto organizacional. Como sugestão para futuras pesquisa, recomenda-se que a proposta apresentada seja contemplada por outras instituições de ensino superior.

Menegon (2018), em sua pesquisa caracterizou o desenvolvimento da inovação nas indústrias de confecções da região oeste de Santa Catarina. Os principais achados da pesquisa indicam que, das empresas participantes, $57,1 \%$ desenvolvem atividades de inovação, $77,1 \%$ realizam investimentos em novas tecnologias incorporadas, além de que, 59,2\% introduziram no mercado algum produto novo ou significativamente melhorado, entre os anos de 2013 e 2017. Para pesquisas futuras, a autora sugere analisar as empresas que não inovam, e também examinar sistematicamente o que leva essas empresas a não inovar.

Pavão (2016) investigou, sob a ótica da Teoria da Contingência, a influência dos fatores contingenciais internos, estratégia, tecnologia e inovação, nos Custos da Qualidade (CQ) e no desempenho percebido de empresas pertencentes ao arranjo de produção local (APL) de confecções nos municípios de Maringá e Cianorte do Estado do Paraná. Elucidou-se que a inovação dos processos influencia os custos de falhas internas e externas. Além disso, verificou-se a existência de influência da inovação de produtos no desempenho organizacional. Para futuros estudos, sugere-se verificar a influência de outros fatores contingenciais nos CQ e no desempenho, como por exemplo, o porte, a estrutura, o estilo de liderança, a cultura organizacional e o ciclo de vida organizacional.

Koch (2018) teve por objetivo em sua pesquisa caracterizar o desenvolvimento do ecossistema de inovação da região de Chapecó. Os achados indicam que a região possui características peculiares em alguns aspectos, o que pode ser justificado pela influência do associativismo e cooperativismo ao longo do tempo, estabelecendo um dogma sobre questões mais inovadoras de mercado, sendo que a desconfiança, em muitos casos, dificulta a inserção de novas concepções e modelos de negócio mais contemporâneos, tendências mundiais. Visando futuras pesquisas, recomenda-se que este estudo seja passível de réplica a 
outros ecossistemas, para ampliar a produção teórica sobre os ecossistemas brasileiros, de forma a revelar os gargalos e possíveis sinergias latentes para a atividade empreendedora e inovadora.

Lappe (2017) buscou caracterizar a gestão da inovação em indústrias agroalimentares da região Oeste Catarinense, segmento este, que, coloca a região em destaque nacional no processamento e industrialização de carnes (suínos e aves). Os achados indicam que, a agroindústria possui um modelo próprio para gerir a inovação, moldado ao longo do tempo a partir da construção de rotinas específicas. Além disso, identificou-se as perspectivas da agroindústria em termos de inovação estratégica, alguns direcionamentos foram aduzidos pelo anseio às limitações da região, com questões de logística, mão de obra, e de preservação ambiental. Assim, recomenda-se que este estudo seja passível de réplica a outros setores produtivos, que detêm maior contato com a inovação, com centros de inovação mais avançados e com gestão pautada em estratégias ofensivas.

Por sua vez, Aquino (2018) analisou como a Investigação Apreciativa (IA) pode contribuir para que seja bem-sucedida a implantação de uma controladoria no âmbito da Auditoria Interna do Instituto Federal de Educação, Ciência e Tecnologia de Pernambuco (AUDI/IFPE). Os resultados indicam que a implantação de uma controladoria no âmbito do IFPE irá fortalecer o sistema de controle interno e dar consecução às três linhas de defesa de gerenciamento de risco e conformidade, constituída pelas gerências/controladoria/auditoria interna da entidade. Com relação aos estudos futuros, o autor espera que possa ser desenvolvido estudos complementares no próprio IFPE, ampliando o horizonte de um trabalho que foi iniciado sob o prisma da quebra de paradigma da inovação e mudança, que tomou a controladoria como ponto de partida.

Zucchi (2013) buscou identificar quais são os fatores indutores e inibidores na utilização das informações contábeis para a adesão aos incentivos fiscais de inovação tecnológica. Os achados indicam que os fatores indutores são dinamismo, heterogeneidade, hostilidade, rentabilidade, lucratividade, alguns instrumentos gerenciais, escopo, confiabilidade e equidade. Quanto aos fatores inibidores, com exceção da confiabilidade que se constitui em fator inibidor, quando esta qualidade não está presente, não foram encontrados outros fatores inibidores que se relacionassem com a utilização da informação contábil em todos os aspectos e em todas fases do processo decisório. $\mathrm{O}$ autor ressalta ser possível uma futura pesquisa que envolva vários anos de adesão aos incentivos e aumentando o universo de empresas envolvidas.

Cruz (2014) investigou a relação entre estilo de liderança, definição de uso do sistema de controle gerencial (SCG) e inovação tecnológica. Dentre os achados, destaca-se que os sistemas de crenças, interativo e de restrições influenciam positivamente a inovação tecnológica, ou seja, as empresas que buscam inovar em seus produtos e processos devem investir na comunicação de valores e objetivos relacionados à inovação; em discussões que envolvam diferentes áreas e membros do negócio e; no estabelecimento de limites que especifiquem um campo de ação para os colaboradores. Por fim, a autora sugere a realização de estudos que explorem as políticas de incentivo e recompensas que têm sido instituídas para promover a inovação.

Picolo (2017) objetivou analisar a relação das ações estruturantes com o desempenho em inovação, mediadas pela dinâmica da maturidade das capacidades em inovação. Nesta direção, testaram-se as relações teóricas propostas neste estudo a partir da técnica estatística de equações estruturais e se confirmaram as hipóteses de pesquisa, corroborando com a tese de que ações estruturantes, mediadas pela maturidade das capacidades em inovação, 
influenciam o desempenho em inovação. Por fim, o autor enfatiza que novos estudos baseados em análises de relações não lineares podem contribuir para aprofundar a compreensão entre as dimensões envolvidas no desempenho em inovação.

Em sua pesquisa, Scholz (2013) teve como principal finalidade apresentar algumas das fontes de financiamento para Inovação existentes no Brasil e sua consistência com as definições do Manual de Oslo. Além disso, teve o objetivo secundário de analisar os montantes investidos e os valores que estão disponíveis para utilização em pesquisa e desenvolvimento de Inovação no Brasil e tecer considerações sobre sua eficácia e eficiência. Dentre os resultados obtidos, o autor verificou que os investimentos em inovação são eficazes, pois, geram novas patentes, havendo, no entanto, espaço para o aumento de sua eficiência, uma vez que apresentam um prazo de quatro anos para maturação.

Por sua vez, Dockhorn (2016) buscou analisar qual a influência da Cultura Organizacional na relação entre Estrutura Formal para Inovação e Processo Criativo. Nesta direção, encontrou-se que esta influência existe, que as características da Estrutura Formal para Inovação são relevantes no Processo Criativo e a relação se intensifica na organização reconhecidamente inovadora. Destarte, a tese "A Cultura Organizacional exerce influência sobre a relação entre Estrutura Formal para Inovação e Processo Criativo" é confirmada. Para futuras pesquisas, sugere-se a aplicação da pesquisa em uma amostra probabilística, em uma única indústria na qual existam, reconhecidamente, empresas criativas e não criativas, com o propósito de redução de possível viés da amostra.

Lopes (2017) explorou a influência das pressões ambientais na formação de redes mediada pelo Sistema de Controle Gerencial (SCG) em incubadoras de empresas. Dentre os achados, destaca-se que as condições econômicas exercem influência sobre o uso do SCG. Já as condições políticas, legais e tecnológicas não apresentaram relação significante com o SCG. O sistema de crenças e os sistemas diagnóstico e interativo de controle influenciam parcialmente no processo de formação de redes de atores. Para futuras pesquisas, a adoção de diferentes técnicas estatísticas pode proporcionar novas interpretações e conclusões diferentes das evidenciadas nesta pesquisa ou mesmo complementar os resultados evidenciados.

Faccini (2015) analisou se as políticas públicas de incentivos fiscais à inovação tecnológica praticadas no Brasil possuem alguma similaridade com aquelas praticadas com o objetivo de estimular o desenvolvimento da inovação tecnológica em outros países do mundo. Dentre os achados, infere-se que há limitações nas normas brasileiras de incentivos em pesquisa e desenvolvimento, especialmente no que diz respeito ao alcance, já que não possibilita que os incentivos alcancem as pequenas e médias empresas, atrasando o aparecimento de tecnologia de ponta no país e resulta em menos competitividade dos produtos e serviços brasileiros no mercado internacional.

Beck (2013) objetivou verificar como a folga organizacional se inter-relaciona com a inovação em uma empresa do setor têxtil. Os achados evidenciam que, na empresa pesquisada, a interface da folga organizacional e inovação ocorre pelo incentivo ao desenvolvimento de inovação em decorrência da capacidade crítica dos funcionários, proporcionada pelo tempo disponibilizado para pensar em como fazer diferente. Dentre as recomendações para pesquisas futuras, a autora sugere a reaplicação do estudo na empresa pesquisada em períodos posteriores, no intuito de acompanhar longitudinalmente este processo da interface entre a folga organizacional e a inovação.

Abreu (2013), em sua tese, avaliou a existência de relações entre estrutura de capital e inovação tecnológica no ambiente brasileiro. Consoante o autor, a avaliação conjunta dos 
resultados demonstra que parece haver uma ligação direta entre estrutura de capital e input de inovação ligado a esforços financeiros, mas que o output de inovação, a priori, ou não possui a mesma força na relação com os indicadores de estrutura de capital, ou apresentam uma relação mais tênue. Com relação as recomendações para futuras pesquisas, o autor propõe investigações que avaliem o relacionamento entre estrutura de capital e inovação tecnológica, a partir de modelos não-lineares.

Por sua vez, Machado (2015) objetivou analisar a relação da aprendizagem organizacional com o desempenho em inovação de produtos sob o efeito moderador das capacidades dinâmicas. Diante os resultados obtidos, a autora sugere que os dirigentes dessas organizações invistam, cada vez mais, na adoção de práticas para adaptação da sua estrutura aos conhecimentos a serem internalizados em seus processos, de maneira que, o produto final tenha um desempenho superior. Para estudos futuros, foi sugerido aplicar novamente 0 modelo proposto em outras regiões do país, a fim de comparar com os resultados desta pesquisa.

Gomes (2013) verificou a influência da cultura de inovação sobre o desempenho em inovação de produtos na indústria têxtil de Santa Catarina. Foi evidenciado que o tamanho da organização não tem influência no desempenho em inovação de produtos, enquanto a localização geográfica impacta significativamente. Os melhores resultados em inovação de produtos foram alcançados pelo Vale do Itajaí, o que pode estar associado aos traços socioculturais da região. Para o autor, a replicação desta pesquisa corrobora também o desenvolvimento da área de estudo, tendo em vista a escassez de trabalhos empíricos sobre cultura de inovação e sua interação com o desenvolvimento de novos produtos.

Em sua tese, Silva (2016) analisou a moderação da aliança estratégica na relação entre capacidade de absorção, inovação e desempenho competitivo, e os procedimentos metodológicos caracterizam a pesquisa como descritiva, por meio de levantamento, de abordagem quantitativa e com corte transversal. Com relação aos achados, conclui-se que a aliança estratégica e a aliança internacional podem ser moderadoras e influenciar a relação entre a capacidade de absorção, a inovação e o desempenho competitivo, nas companhias brasileiras de capital aberto. Dentre as recomendações para pesquisas futuras, recomenda-se a visão de negócios em rede, e não somente a análise didática das alianças estratégicas.

Por fim, a pesquisa de Bernardi (2018) teve o objetivo de analisar as contribuições das ações de desenvolvimento e fortalecimento de startups do Programa StartupSC, importante Programa de Desenvolvimento de Startups de Santa Catarina. Os resultados indicam que o Programa StartupSC vem desenvolvendo ações de grande relevância e que tem influenciado diretamente no sucesso das startups participantes. Alguns indicadores estudados junto às startups certificaram que um programa como este pode ser um divisor de águas no estágio inicial de uma startup. Para estudos complementares aos resultados obtidos nesta pesquisa, sugere-se um possível cruzamento entre as perguntas do instrumento de coleta de dados a fim de elucidar outros aspectos e ainda ocultos.

\section{CONSIDERAÇÕES FINAIS}

O escopo desta pesquisa foi analisar o cenário nacional da produção científica sobre a inovação, por meio de uma revisão sistemática. Assim sendo, foi empregada uma metodologia quantitativa e qualitativa, visando responder as etapas estabelecidas para execução do estudo. Destarte, com o intuito de aprofundar o conhecimento científico acerca da inovação e elucidar a evolução das pesquisas sobre a temática, a presente pesquisa pautou-se no seguinte questionamento: Qual é o cenário das discussões sobre inovação evidenciadas nos 
trabalhos de conclusão dos cursos stricto sensu (mestrado e doutorado) em contabilidade do Brasil?

Sob esse viés, a seleção das teses e dissertações que abordaram a temática inovação foi realizada no banco de Teses e Dissertações da Capes, de modo que resultou em uma totalidade de 27 pesquisas após a aplicação dos filtros. Assim, a primeira análise referiu-se ao ano de publicação. A análise quantitativa evidenciou que o ano com mais publicação foi o de 2018 (com 11 pesquisas), seguido por 2013 (com 5 pesquisas), 2017 (com 4 pesquisas), 2016 (com 3 pesquisas), 2015 (com 2 pesquisas) e, 2012 e 2014 (com apenas uma pesquisa cada).

Com relação as instituições que se evidenciam em publicações, destaca-se a Universidade Regional de Blumenau (FURB) com 8 trabalhos, sendo que 6 deles são em nível de doutorado (teses). Já com relação aos trabalhos em nível de mestrado (dissertações) destaca-se a Universidade Comunitária da Região de Chapecó (UNOCHAPECÓ) com 6 pesquisas. Além disso, em se tratando dos programas de pós-graduação, destaca-se o Programa de Pós-Graduação em Ciências Contábeis com 13 trabalhos, sendo que 6 são teses.

Nessa perspectiva, respondendo à questão de pesquisa "Qual é o cenário das discussões sobre inovação, evidenciadas nos trabalhos de conclusão dos cursos stricto sensu (mestrado e doutorado) em contabilidade do Brasil, verifica-se que se trata de circunstâncias variadas, que proporcionam lacunas de pesquisas futuras diversas. Além disso, evidenciou-se que há escassez de estudos em nível de mestrado e doutorado acerca da inovação em microempresas e empresas de pequeno porte. Tal fato desperta a preocupação pela importância da inovação neste segmento empresarial, para a sobrevivência e consolidação em um cenário cada vez mais competitivo e globalizado.

Ao analisar sistematicamente as teses e dissertações desenvolvidas nos programas de pós-graduação stricto sensu da área de Ciências Contábeis do Brasil e evidenciar as lacunas relacionadas a temática inovação ainda não preenchidas, a presente pesquisa vem a ser um alicerce para futuros estudos da área. Ademais, por não ter outros estudos que analisam sistematicamente as produções científicas deste segmento acadêmico, contribui com a literatura em termos de ineditismo. Em se tratando das implicações práticas, alerta os existentes e futuros programas de pós-graduação da área no que se refere ao número extremamente baixo de pesquisas que abordam a temática inovação e estimula a multiplicação deste número com a elucidação das diversas lacunas de pesquisa relacionadas a temática inovação.

Por ser uma pesquisa científica, o presente estudo apresenta algumas limitações. Entretanto, as referidas limitações tornam possível a constatação de oportunidades de novas pesquisas. Uma das limitações desta revisão refere-se a base escolhida e à escolha de uma única palavra-chave para delimitar o tema. Destarte, sugere-se para futuras revisões abranger outras bases e também a inclusão de outras palavras-chave. Além disso, como esta revisão abrangeu apenas a área de Ciências Contábeis, recomenda-se que estudos futuros analisem sistematicamente trabalhos de outras áreas como Administração, onde é possível encontrar um número maior de estudos.

\section{AGRADECIMENTOS}

Este trabalho foi realizado com apoio da Coordenação de Aperfeiçoamento de Pessoal de Nível Superior - Brasil (CAPES) - Código de Financiamento 001. 


\section{REFERÊNCIAS}

ABREU, E. S. Inovação tecnológica e estrutura de capital: um estudo em empresas brasileiras de capital aberto. 2013. Dissertação (Mestrado em Contabilidade) - Universidade Federal da Bahia, Salvador, 2013.

AFUAH, A. Innovation management: strategies, implementation, and profits. New York: Oxford University Press, 2003.

AQUINO, M. M. F. Inovação e mudança na auditoria interna do Instituto Federal de Educação, Ciência e Tecnologia de Pernambuco: a contribuição da investigação apreciativa. 2018. Dissertação (Mestrado em Controladoria) - Universidade Federal Rural de Pernambuco, Recife, 2018.

BACINELLO, E. Influência da maturidade em responsabilidade social corporativa e inovação sustentável no desempenho de empresas brasileiras. 2018. Tese (Doutorado em Ciências Contábeis e Administração) - Universidade Regional de Blumenau, Blumenau, 2018.

BECK, F. Interfaces da folga organizacional com inovação: um estudo em empresa têxtil. 2013. Dissertação (Mestrado em Ciências Contábeis) - Universidade Regional de Blumenau, Blumenau, 2013.

BERNARDI, E. R. Estudo das contribuições das ações de desenvolvimento e fortalecimento de startups do projeto Startupsc. 2018. Dissertação (Mestrado em Ciências Contábeis e Administração) Universidade Comunitária da Região de Chapecó, Chapecó, 2018.

BESSANT, J.; TIDD, J. Inovação e empreendedorismo. (E. R. BECKER; G. PERIZZOLO; P. L. F. CUNHA, Trad. Porto Alegre: Bookman, 2009.

BETZ, F. Managing Technological Innovation: competitive advantage from change. New York: A Wiley-Interscience Publication, 1998.

CASTRO, A. A. Revisão sistemática e meta-análise. Compacta: temas de cardiologia, v. 3, n. 1, p. 5-9, 2001.

CONDEIXA, G. A. A relação entre ciência, tecnologia e inovação e o empreendedorismo de alto crescimento. 2016. Dissertação (Mestrado em Administração) - Universidade Federal de Goiás, Goiânia, 2016.

CORREIA, G. K S. Estudo de caso: papel da controladoria na gestão de empresas inovadoras. 2018. Dissertação (Mestrado em Ciências Contábeis) - Fundação Escola de Comércio Álvares Penteado, São Paulo, 2018.

COSTA, A. C. R.; ROCHA, E. R. P. Panorama da cadeia produtiva têxtil e de confecções e a questão da inovação. BNDES Setorial, s. I, v. 29, p. 159-202, 2009.

CRUZ, A. P. C. Estilo de liderança, sistema de controle gerencial e inovação tecnológica: papel dos sistemas de crenças, interativo, diagnóstico e de restrições. 2014. Tese 
(Doutorado em Controladoria e Contabilidade) - Universidade de São Paulo, São Paulo, 2014.

CUNICO, A. K. Do artesanal ao profissional: tipologia e capacidades estratégicas das microcervejarias da mesorregião do oeste catarinense. 2018. Dissertação (Mestrado em Ciências Contábeis e Administração) - Universidade Comunitária da Região de Chapecó, Chapecó, 2018.

DOCKHORN, M. S. M. Influência da cultura organizacional na relação entre estrutura formal para inovação e processo criativo: estudo em ambientes organizacionais. 2016. Tese (Doutorado em Ciências Contábeis e Administração) - Universidade Regional de Blumenau, Blumenau, 2016.

FACCINI, L. E. incentivos fiscais à pesquisa, desenvolvimento e inovação tecnológica no Brasil: uma análise da Lei do Bem. 2015. Dissertação (Mestrado em Ciências Contábeis e Atuarias) - Pontifícia Universidade Católica de São Paulo, São Paulo, 2015.

GOMES, G. Cultura de inovação e sua influência no desempenho em inovação de produtos na indústria têxtil de Santa Catarina. 2013. Tese (Doutorado em Ciências Contábeis e Administração) - Universidade Regional de Blumenau, Blumenau, 2013.

GOMES, T. Influência da resiliência do gestor na formação de redes moderada pela prioridade estratégica de inovação em empresas incubadas. 2018. Dissertação (Mestrado em Contabilidade) - Universidade Federal de Santa Catarina, Florianópolis, 2018.

KITCHENHAM, B. Procedures for performing systematic reviews. Keele, UK, Keele University, v. 33, p. 1-26, 2004.

KOCH, L. L. Ecossistemas de inovação: estudo da região de Chapecó. 2018. Dissertação (Mestrado em Ciências Contábeis e Administração) - Universidade Comunitária da Região de Chapecó, Chapecó, 2018.

LAPPE, L. Atuação prática em inovação: um estudo em uma indústria agroalimentar do oeste catarinense. 2017. Dissertação (Mestrado em Ciências Contábeis e Administração) Universidade Comunitária da Região de Chapecó, Chapecó, 2017.

LOPES, I. F. Influência de pressões ambientais na formação de redes mediada pelo sistema de controle gerencial em incubadoras de empresas. 2017. Dissertação (Mestrado em Contabilidade) - Universidade Federal de Santa Catarina, Florianópolis, 2017.

MACHADO, M. M. Aprendizagem organizacional e sua relação com o desempenho em inovação de produtos moderada pelas capacidades dinâmicas. 2015. Tese (Doutorado em Ciências Contábeis e Administração) - Universidade Regional de Blumenau, Blumenau, 2015.

MENEGON, E. M. P. Inovação nas indústrias de confecções da região oeste de Santa Catarina. 2018. Dissertação (Mestrado em Ciências Contábeis e Administração) Universidade Comunitária da Região de Chapecó, Chapecó, 2018. 
MOHER, D.; LIBERATI, A.; TETZLAFF, J.; ALTMAN, D. G. Reprint-preferred reporting items for systematic reviews and meta-analyses: the PRISMA statement. Physical Therapy, v. 89, n. 9, p. 873-880, 2009. https://doi.org/10.1093/ptj/89.9.873

PAVÃO, J. A. A Influência da estratégia, tecnologia e inovação na gestão dos custos da qualidade e no desempenho: um levantamento em empresas do APL de confecções. 2016. Dissertação (Mestrado em Ciências Contábeis) - Universidade Estadual de Maringá, Maringá, 2016.

PICOLO, J. D. Relação das ações estruturantes com o desempenho em inovação mediadas pela dinâmica da maturidade das capacidades em inovação. 2017. Tese (Doutorado em Ciências Contábeis e Administração) - Universidade Regional de Blumenau, Blumenau, 2017.

PRADO, A. C. L. Inovação nas indústrias vitivinícolas do Alto Vale do Rio do Peixe/SC. 2018. Dissertação (Mestrado em Ciências Contábeis e Administração) - Universidade Comunitária da Região de Chapecó, Chapecó, 2018.

ROGERS, E. M. Diffusion of Innovations. Nova York: The Free Press, 1995.

ROUSSEL, P. A.; SAAD, K. N.; ERICKSON, T. J. Third Generation R\&D: Managing the link to corporate strategy. Boston: Harvard Business School Press, 1991.

SCHIAVI, G. S. Potenciais modelos de negócios disruptivos para a área contábil. 2018. Dissertação (Mestrado em Controladoria e Contabilidade) - Universidade Federal do Rio Grande do Sul, Porto Alegre, 2018.

SCHOLZ, L. F. B. Estudo das fontes de financiamentos públicas dos processos ou projetos de inovação. 2013. Dissertação (Mestrado em Ciências Contábeis e Atuárias) - Pontifícia Universidade Católica de São Paulo, São Paulo, 2013.

SCHUMPETER, J. A. A teoria do desenvolvimento econômico. São Paulo: Nova Cultural, 1988.

SILVA, G. Relação entre capacidade de absorção, inovação e desempenho competitivo, moderada pela aliança estratégica. 2016. Tese (Doutorado em Ciências Contábeis e Administração) - Universidade Regional de Blumenau, Blumenau, Brasil, 2016.

SIMONS, R. Levers of Control. How managers use innovative control systems to drive strategic renewal. Massachusetts: Harvard Business School Press Boston, 1995.

SOUZA, F. F. Relação entre inovação e adoção de práticas modernas de contabilidade gerencial. 2017. Dissertação (Mestrado em Contabilidade) - Universidade Federal de Santa Catarina, Florianópolis, 2017.

SOUZA, G. P. Delineamento da controladoria segundo a perspectiva da abordagem apreciativa: a experiência em uma Instituição de Ensino Superior. 2018. Dissertação (Mestrado em Controladoria) - Universidade Federal Rural de Pernambuco, Recife, 2018. 
TIDD, J.; BESSANT, J. Gestão da inovação. 5. ed. Tradução Félix Nonnenmacher. Porto Alegre: Bookman, 2015.

TIGRE, P. B. Gestão da inovação: a economia da tecnologia do Brasil. Rio de Janeiro: Elsevier, 2006.

UTZIG, M. J. S. Relação do uso interativo de instrumentos do sistema de controle gerencial com diferentes modelos de gestão de inovação de empresas. 2012. Dissertação (Mestrado em Ciências Contábeis) - Universidade Regional de Blumenau, Blumenau, 2012.

VAN DE VEN, A. H. Central problems in the management of innovation. Management Science, v. 32, n. 5, p. 590-607, 1986. https://doi.org/10.1287/mnsc.32.5.590

WOJAHN, R. M. Determinantes da inovação e o desempenho de novos produtos em empresas da indústria moveleira. 2015. Dissertação (Mestrado em Administração) Universidade Regional de Blumenau, Blumenau, 2015.

ZORZO, L. S. A Relação entre o foco em inovação e o impacto na eficiência: Um estudo nas empresas brasileiras distribuidoras de energia elétrica. 2015. Dissertação (Mestrado em Ciências Contábeis) - Universidade do Vale do Rio dos Sinos, São Leopoldo, 2015.

ZUCCHI, A. L. Utilização da informação contábil na adesão aos incentivos fiscais de inovação tecnológica estabelecidos pela Lei $\mathbf{N}^{\circ}$ 11.196/2005. 2013. Tese (Doutorado em Controladoria e Contabilidade) - Universidade de São Paulo, São Paulo, Brasil, 2013. 